\title{
Deformation Behavior and Microstructure Evolution of NiTiCu Shape Memory Alloy Subjected to Plastic Deformation at High Temperatures
}

\author{
Shuyong Jiang ${ }^{1, *}$, Dong Sun ${ }^{2}$, Yanqiu Zhang ${ }^{1}$ and $\mathrm{Li} \mathrm{Hu}{ }^{2}$ \\ 1 College of Mechanical and Electrical Engineering, Harbin Engineering University, Harbin 150001, China; \\ zhangyq@hrbeu.edu.cn \\ 2 College of Materials Science and Chemical Engineering, Harbin Engineering University, Harbin 150001, \\ China; 18845143035@163.com (D.S.); heu_huli@126.com (L.H.) \\ * Correspondence: jiangshuyong@hrbeu.edu.cn; Tel.: +86-451-8251-9710
}

Received: 15 July 2017; Accepted: 27 July 2017; Published: 3 August 2017

\begin{abstract}
Deformation behavior and microstructure evolution of NiTiCu shape memory alloy (SMA), which possesses martensite phase at room temperature, were investigated based on a uniaxial compression test at the temperatures of $700 \sim 1000{ }^{\circ} \mathrm{C}$ and at the strain rates of $0.0005 \sim 0.5 \mathrm{~s}^{-1}$. The constitutive equation of NiTiCu SMA was established in order to describe the flow characteristic of NiTiCu SMA, which is dominated by dynamic recovery and dynamic recrystallization. Dislocations become the dominant substructures of martensite phase in NiTiCu SMA compressed at $700{ }^{\circ} \mathrm{C}$. Martensite twins are dominant in NiTiCu SMA compressed at 800 and $900{ }^{\circ} \mathrm{C}$. Martensite twins are not observed in NiTiCu SMA compressed at $1000^{\circ} \mathrm{C}$. The microstructures resulting from dynamic recovery or dynamic recrystallization significantly influences the substructures in the martensite phase of NiTiCu SMA at room temperature. Dislocation substructures formed during dynamic recovery, such as dislocation cells and subgrain boundaries, can suppress the formation of twins in the martensite laths of NiTiCu SMA. The size of dynamic recrystallized grains affects the formation of martensite twins. Martensite twins are not easily formed in the larger recrystallized grain, since the constraint of the grain boundaries plays a weak role. However, in the smaller recrystallized grain, martensite twins are induced to accommodate the transformation from austenite to martensite.
\end{abstract}

Keywords: shape memory alloy; NiTiCu alloy; constitutive behavior; phase transformation; microstructure

\section{Introduction}

NiTi shape memory alloys (SMAs) have deserved increasing attention in the engineering field because they have shape memory effect [1]. With a view to widening the application of NiTi SMA in the domain of engineering, third elements are added to the binary NiTi SMA in order to change the transformation temperature or hysteresis [2-6]. For example, $\mathrm{Cu}$ element is added to binary NiTi SMA so as to significantly lower the phase transformation hysteresis, which lays the foundation for the application of an actuator or micro-electro-mechanical system (MEMS) [7,8]. As a consequence, over the last few decades, many researchers have paid more attention to NiTiCu SMAs [9-12]. It is well known that plastic deformation substantially influences the microstructures and transformation behavior of NiTi-based SMAs $[13,14]$. In particular, thermomechanical processing, especially plastic working, is an important step in manufacturing NiTi-based SMA products [15]. Consequently, it is very important to understand deformation behavior as well as microstructural evolution of NiTi-based SMAs at high temperatures [16-20]. Up to date, many scholars have devoted themselves to studying the flow behavior of NiTi-based SMAs at high temperatures based on the Arrhenius-type constitutive equation [21-25], which lays the foundation for clarifying deformation mechanisms of NiTi-based SMAs. 
In the present study, the deformation behavior and microstructure evolution of $\mathrm{Ni}_{45} \mathrm{Ti}_{50} \mathrm{Cu}_{5}(\mathrm{at} \%)$ SMA were investigated based on a uniaxial compression test, where the temperatures range from 700 to $1000{ }^{\circ} \mathrm{C}$ and the strain rates range from 0.0005 to $0.5 \mathrm{~s}^{-1}$. In particular, the $\mathrm{Ni}_{45} \mathrm{Ti}_{50} \mathrm{Cu}_{5} \mathrm{SMA}$ of interest possesses martensite phase at room temperature. Therefore, it is of great significance to investigate the deformation behavior and microstructure evolution of $\mathrm{Ni}_{45} \mathrm{Ti}_{50} \mathrm{Cu}_{5} \mathrm{SMA}$.

\section{Materials and Methods}

As-rolled $\mathrm{Ni}_{45} \mathrm{Ti}_{50} \mathrm{Cu}_{5}$ (at \%) SMA bar with a diameter of $30 \mathrm{~mm}$ was commercially received from Xi'an Saite Metal Materials Development Co., Ltd. (Xi'an, China). The phase transformation of the as-rolled NiTiCu SMA was measured using Pyris Diamond type differential scanning calorimetry (DSC, Perkin Elmer Inc., Waltham, MA, USA). The DSC test was carried out in the range of $-150 \sim 150{ }^{\circ} \mathrm{C}$, where the heating and cooling steps were $10^{\circ} \mathrm{C} / \mathrm{min}$. The DSC curve of the as-rolled $\mathrm{NiTiCu}$ SMA can be found in Reference [26]. The phase transformation temperatures of the as-rolled NiTiCu SMA were as follows: $M_{s}=53.8^{\circ} \mathrm{C}, M_{f}=8.3^{\circ} \mathrm{C}, A_{s}=73.1{ }^{\circ} \mathrm{C}$ and $A_{f}=113.5^{\circ} \mathrm{C}$.

NiTiCu SMA samples, which possess a height of $9 \mathrm{~mm}$ and a diameter of $6 \mathrm{~mm}$, were electro-discharge machined from the as-rolled NiTiCu SMA bar. Subsequently, they were used for the compression test. An INSTRON-5500R universal material testing machine (Instron Corporation, Norwood, MA, USA) was used for implementing the compression tests. The NiTiCu SMA samples were compressed by the deformation extent of $60 \%$, where the temperatures range from 700 to $1000{ }^{\circ} \mathrm{C}$ and the strain rates range from 0.0005 to $0.5 \mathrm{~s}^{-1}$. Subsequently, all of the compressed $\mathrm{NiTiCu}$ SMA specimens were put into ice water for the purpose of guaranteeing complete martensite phase transformation.

As for the as-rolled and compressed NiTiCu SMA samples, the microstructures were captured by transmission electron microscopy (TEM). The NiTiCu SMA samples used for TEM observation were made into foils with the thickness of $70 \mu \mathrm{m}$ by means of mechanical grinding. Subsequently, the foils were thinned by twin-jet polishing in an electrolyte which is composed of $6 \% \mathrm{HClO}_{4}$, $34 \% \mathrm{CH}_{3}\left(\mathrm{CH}_{2}\right)_{3} \mathrm{OH}$, and $60 \% \mathrm{CH}_{3} \mathrm{OH}$ by volume fraction. Finally, the NiTiCu SMA samples for TEM observation were characterized by virtue of an FEI TECNAI G2 F30 microscope (FEI Corporation, Hillsboro, OR, USA). TEM observation results indicate that the substructure of martensite phase contains martensite laths and martensite twins, as shown in Figure 1.
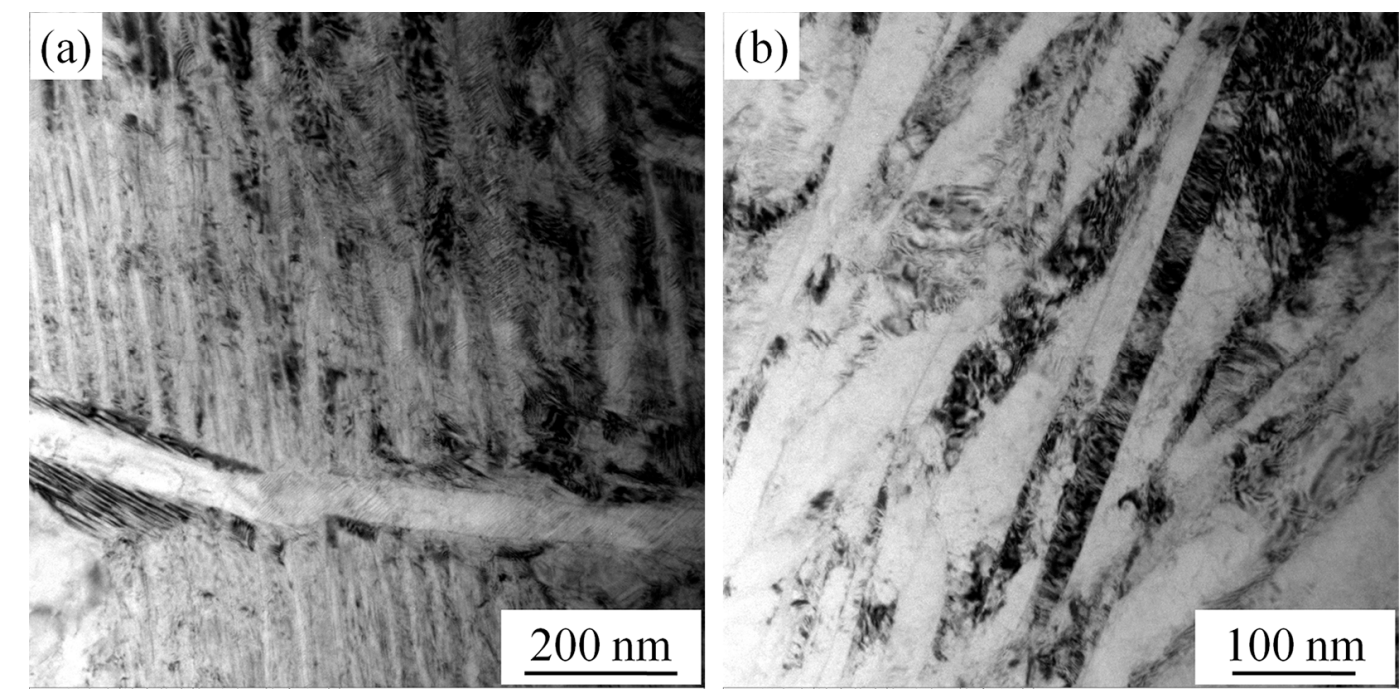

Figure 1. Transmission electron microscope (TEM) micrographs of as-rolled NiTiCu shape memory alloy (SMA): (a) Bright field image indicating martensite twins; (b) Bright field image indicating martensite laths. 


\section{Results and Discussion}

\subsection{Deformation Behavior of NiTiCu SMA}

Figure 2 indicates the true stress-strain curves of NiTiCu SMA undergoing uniaxial compression at the temperatures ranging from 700 to $1000{ }^{\circ} \mathrm{C}$ and the strain rates ranging from 0.0005 to $0.5 \mathrm{~s}^{-1}$. As can be seen in Figure 3, the flow stress of NiTiCu SMA increases with increasing strain rate. Furthermore, elevating the temperature contributes to lowering the flow stress of NiTiCu SMA. It can be noted from the stress-strain curves of NiTiCu SMA that dynamic recovery (DRV) or dynamic recrystallization (DRX) can occur during compression deformation.

(a)

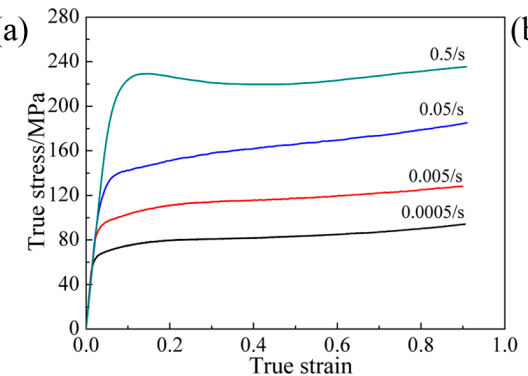

(c)

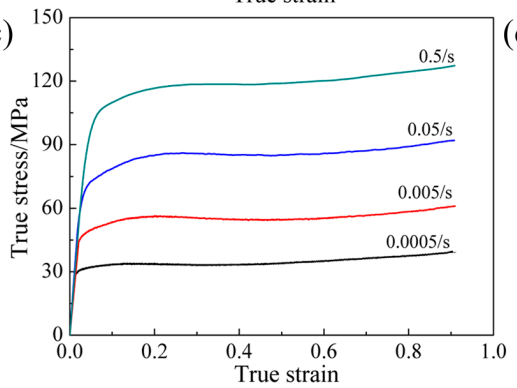

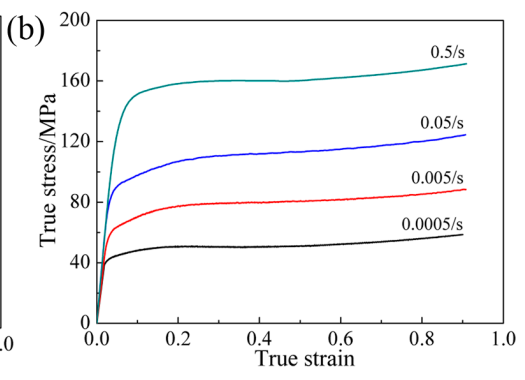

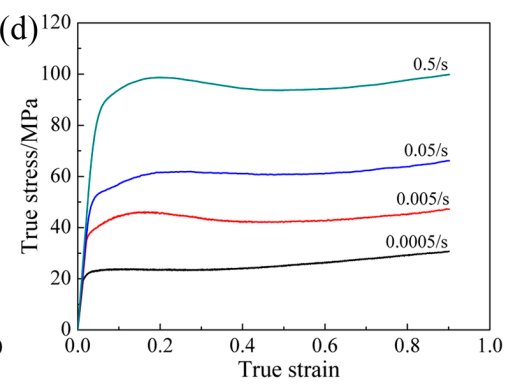

Figure 2. True stress-strain curves of NiTiCu SMA undergoing uniaxial compression at various strain rates and temperatures: (a) $700{ }^{\circ} \mathrm{C}$; (b) $800{ }^{\circ} \mathrm{C}$; (c) $900{ }^{\circ} \mathrm{C}$; (d) $1000{ }^{\circ} \mathrm{C}$.
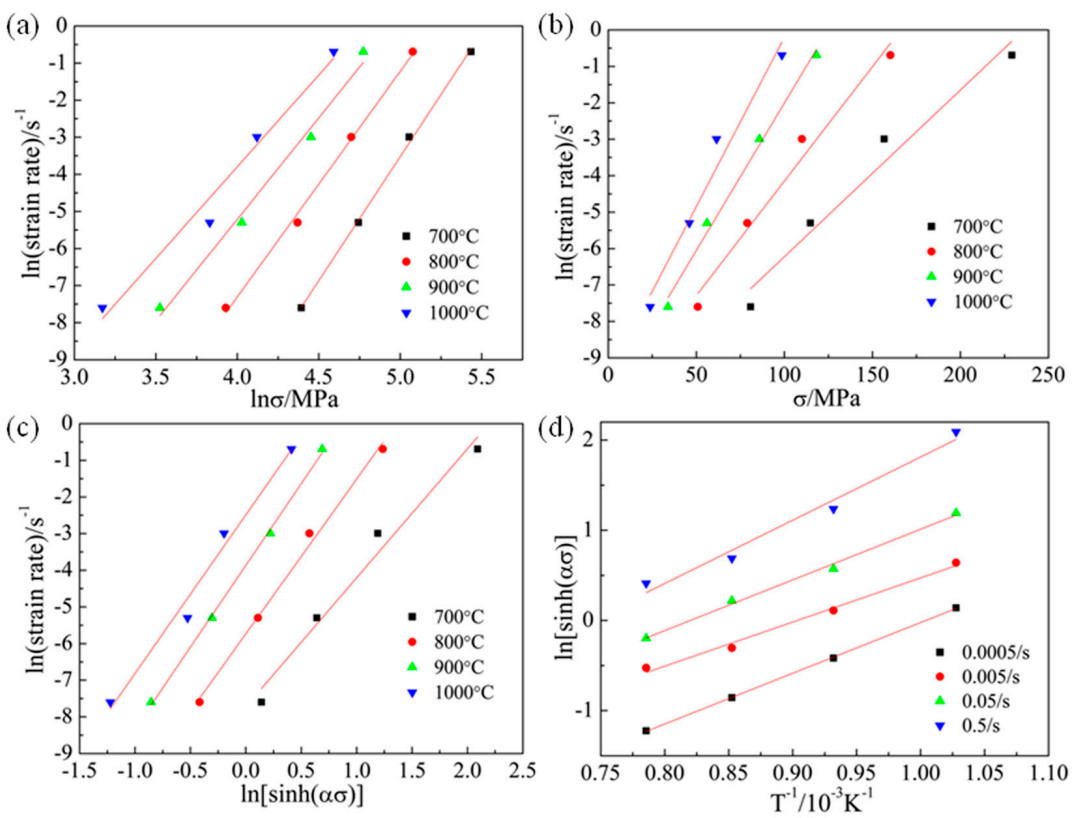

Figure 3. Determination of material constants by means of fitting method based on experimental data: (a) Solving the value of $n$; (b) Solving the value of $\beta$; (c) Modifying the value of $n$; (d) Solving the value of $Q$. 
Based on the stress-strain curves of NiTiCu SMA at high temperatures, it can be found that the plastic flow of NiTiCu SMA at high temperatures is dependent on the strain rates as well as the deformation temperatures. As a consequence, the constitutive equation of NiTiCu SMA at high temperatures is established according to the Arrhenius type equation [22-25], namely:

$$
\dot{\varepsilon}=A[\sinh (\alpha \sigma)]^{n} \exp \left(-\frac{Q}{\mathrm{RT}}\right)
$$

where $\dot{\varepsilon}$ is the strain rate, $\sigma$ the flow stress, $T$ the absolute temperature, $Q$ the activation energy, $\mathrm{R}$ the universal gas constant $\left(8.314 \mathrm{~J} \cdot \mathrm{mol}^{-1} \cdot \mathrm{K}^{-1}\right)$, and $A, \alpha$ and $n$ the material constants.

At a low stress level, Equation (1) is approximately expressed by:

$$
\dot{\varepsilon}=A_{1} \sigma^{n} \exp \left(-\frac{Q}{R T}\right), \alpha \sigma \leq 0.83373
$$

where $A_{1}$ is still a material constant and $A_{1}=A \alpha^{n}$.

At a high stress level, Equation (1) is approximately simplified as:

$$
\dot{\varepsilon}=A_{2} \exp (\beta \sigma) \exp \left(-\frac{Q}{\mathrm{RT}}\right), \alpha \sigma \leq 1.60944
$$

where $A_{2}$ and $\beta$ remain the material constants and $A_{2}=\frac{A}{2^{n}}, \beta=n \alpha$.

It is generally accepted that the Zener-Hollomon parameter $Z$, which is viewed as the function of strain rate and temperature, can be expressed as follows:

$$
Z=\dot{\varepsilon} \exp \left(\frac{Q}{R T}\right)
$$

Substituting the parameter $Z$ into Equation (1) leads to:

$$
\mathrm{Z}=A[\sinh (\alpha \sigma)]^{n}
$$

The following equation can be obtained by transforming Equation (5):

$$
\sigma=\frac{1}{\alpha} \ln \left\{\left(\frac{Z}{A}\right)^{\frac{1}{n}}+\sqrt{\left(\frac{Z}{A}\right)^{\frac{2}{n}}+1}\right\}
$$

As a consequence, Equation (6) is the constitutive equation which is expressed by the parameter $Z$.

The constitutive equation of NiTiCu SMA can be obtained after the values of $A, \alpha, n$, and $Q$ can be determined on the basis of the experimental data. In the present work, the peak stress is used to determine the corresponding parameters, as shown in Table 1.

Table 1. Peak stress of NiTiCu SMA at the various strain rates and deformation temperatures (MPa).

\begin{tabular}{cccccc}
\hline \multirow{2}{*}{$\dot{\varepsilon} / \mathbf{s}^{-1}$} & \multirow{2}{*}{$\dot{\boldsymbol{\varepsilon}}$} & \multicolumn{4}{c}{$\mathbf{T} / \mathbf{K}$} \\
\cline { 3 - 6 } & & $\mathbf{9 7 3}$ & $\mathbf{1 0 7 3}$ & $\mathbf{1 1 7 3}$ & $\mathbf{1 2 7 3}$ \\
\hline 0.0005 & -7.6009 & 80.878 & 50.8828 & 33.95 & 23.8579 \\
0.005 & -5.2983 & 114.8027 & 79.0071 & 56.1214 & 46.1041 \\
0.05 & -2.9957 & 156.7221 & 109.9611 & 85.8336 & 61.5655 \\
0.5 & -0.6931 & 229.1717 & 160.2669 & 118.3127 & 98.6517 \\
\hline
\end{tabular}

To solve the value of $n$, the following equation can be obtained by employing the natural logarithm for Equation (2): 


$$
\ln \dot{\varepsilon}=\ln A_{1}+n \ln \sigma-\frac{Q}{\mathrm{RT}}
$$

According to Equation (7), the value of $n$ can be obtained by means of the linear fitting method on the basis of experimental data, as shown in Figure 3a. The value of $n$ is determined as 5.7988.

Prior to obtaining the value of $\alpha$, the value of $\beta$ needs to be determined by employing the natural logarithm of Equation (3), and consequently the following equation is obtained:

$$
\ln \dot{\varepsilon}=\ln A_{2}+\beta \sigma-\frac{Q}{\mathrm{R} T}
$$

In the same manner, the value of $n$ can be obtained by virtue of the linear fitting method on the basis of experimental data, as shown in Figure $3 \mathrm{~b}$. As a consequence, the value of $\beta$ is calculated as 0.07059 . Finally, according to the values of $n$ and $\beta$, the value of $\alpha$ can be determined as $\alpha=\beta / n=1.217 \times 10^{-2} \mathrm{MPa}$.

In order to further modify the value of $n$, the following equation can be obtained by employing the natural logarithm of Equation (1):

$$
\ln \dot{\varepsilon}=\ln A+n \ln [\sinh (\alpha \sigma)]-\frac{Q}{\mathrm{RT}}
$$

Similarly, the value of $n$ can be modified as 4.1318 according to the linear fitting method on the basis of experimental data, as shown in Figure 3c.

For the purpose of obtaining the value of $Q$, in the case of the given strain rates, the following equation can be obtained by differentiating $T^{-1}$ in Equation (9):

$$
Q=n R\left(\frac{\partial \ln [\sinh (\alpha \sigma)]}{\partial T^{-1}}\right)_{\dot{\varepsilon}}
$$

The value of $Q$ can be determined as $198.84 \times 103 \mathrm{~J} \cdot \mathrm{mol}^{-1}$ by combining the modified value of $n$ and the value of $R$ with the fitting value derived from Figure $3 \mathrm{~d}$.

For the purpose of obtaining the value of $A$, the following equation can be obtained by employing the natural logarithm of Equation (5):

$$
\ln Z=\ln A+n \ln [\sinh (\alpha \sigma)]
$$

According to Equation (11), the value of $\ln A$ can be determined as 16.3994 based on the experimental data, as shown in Figure 4, and consequently the value of $A$ is further calculated to be $1.3249 \times 10^{7}$.

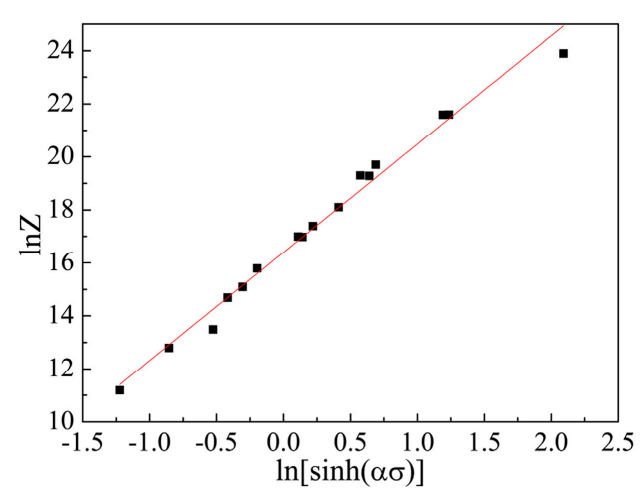

Figure 4. Determination of material constant A based on the relationship between $\ln Z$ and $\ln [\sinh (\alpha \sigma)]$. 
As a consequence, the constitutive equation of NiTiCu SMA is represented by the following two equations:

$$
\begin{gathered}
\dot{\varepsilon}=1.3249 \times 10^{7}\left[\sinh \left(1.217 \times 10^{-2} \sigma\right)\right]^{4.1318} \exp \left(\frac{-1.9884 \times 10^{5}}{\mathrm{RT}}\right) \\
\sigma=82.17 \ln \left[\left(\frac{Z}{A}\right)^{\frac{1}{4.1318}}+\sqrt{\left.\left(\frac{Z}{A}\right)^{\frac{2}{4.1318}}+1\right]}\right.
\end{gathered}
$$

\subsection{Microstructural Evolution of NiTiCu SMA}

The microstructural evolution of several representative NiTiCu SMA samples, which undergo compression deformation, is captured in order to reveal the corresponding plastic deformation mechanisms at high temperatures. It can be generally accepted that DRV or DRX can take place when metallic alloy experiences plastic deformation at elevated temperatures. In the case of DRX, in particular, the size of the recrystallized grains increases with increasing the deformation temperature or decreasing the strain rate. According to the phase transformation temperatures of NiTiCu SMA, it can be noted that when NiTiCu SMA samples are subjected to compression deformation at high temperatures and are quenched into the ice water, they are transformed from B2 austenite into B19' martensite because of complete martensite phase transformation.

For the purpose of better revealing the martensite structure of NiTiCu SMA, TEM micrographs of the NiTiCu SMA samples, which are subjected to compression at the temperatures of $700 \sim 1000{ }^{\circ} \mathrm{C}$ at the strain rate of $0.005 \mathrm{~s}^{-1}$, were captured, as shown in Figures 5-8.

It can be found that dislocation substructures, such as dislocation cells and subgrain boundaries, appear in the martensite phase of NiTiCu SMA subjected to compression deformation at $700{ }^{\circ} \mathrm{C}$, as shown in Figure 5a. It can thus be concluded that dislocations become the dominant substructures of martensite phase in the NiTiCu SMA specimen undergoing compression at $700{ }^{\circ} \mathrm{C}$. Martensite twins are dominant in the NiTiCu SMA specimen undergoing compression at 800 and $900{ }^{\circ} \mathrm{C}$, as shown in Figures 6 and 7. However, martensite twins are not observed in the NiTiCu SMA specimen undergoing compression at $1000^{\circ} \mathrm{C}$, as shown in Figure 8. According to the aforementioned analysis, it is noted that DRV or DRX can occur in NiTiCu SMA samples subjected to compression deformation at high temperatures, which depends on the deformation temperatures. It can be deduced that DRV or DRX microstructures have an influence on the substructures of martensite phase of NiTiCu SMA. In general, DRV is the dominant mechanism when NiTi-based SMAs are subjected to compression deformation at $700{ }^{\circ} \mathrm{C}$ [21]. As a consequence, DRV leads to the deformation of grains and thus dislocation substructures, such as dislocation cells and subgrain boundaries, are formed in the grain interior. These dislocation substructures are kept in the martensite phase of the NiTiCu SMA sample during subsequent martensite phase transformations. These retained dislocation substructures suppress the formation of martensite twins. It can be generally accepted that complete DRX can take place in NiTi-based SMAs suffering from compression at temperatures above $800{ }^{\circ} \mathrm{C}[18,21]$. It is proposed that the size of the dynamic recrystallized grains influences the formation of martensite twins in $\mathrm{NiTiCu}$ SMAs. In general, the size of the dynamic recrystallized grains increases with increasing the deformation temperature [18]. Furthermore, it is generally accepted that the occurrence of martensite twins aims to accommodate the formation of martensite phase during the transformation from $\mathrm{B} 2$ austenite to B19' martensite. It can be inferred that when the dynamic recrystallized grains possess a smaller size, the grain boundaries are able to suppress the formation of martensite phase. Consequently, the occurrence of martensite twins contributes to the formation of martensite phase. When the dynamic recrystallized grains possess a larger size, there is sufficient space to guarantee the formation of martensite phase in the grain interior. Therefore, martensite twins are not easily formed in NiTiCu SMA samples subjected to compression deformation at $1000{ }^{\circ} \mathrm{C}$. 

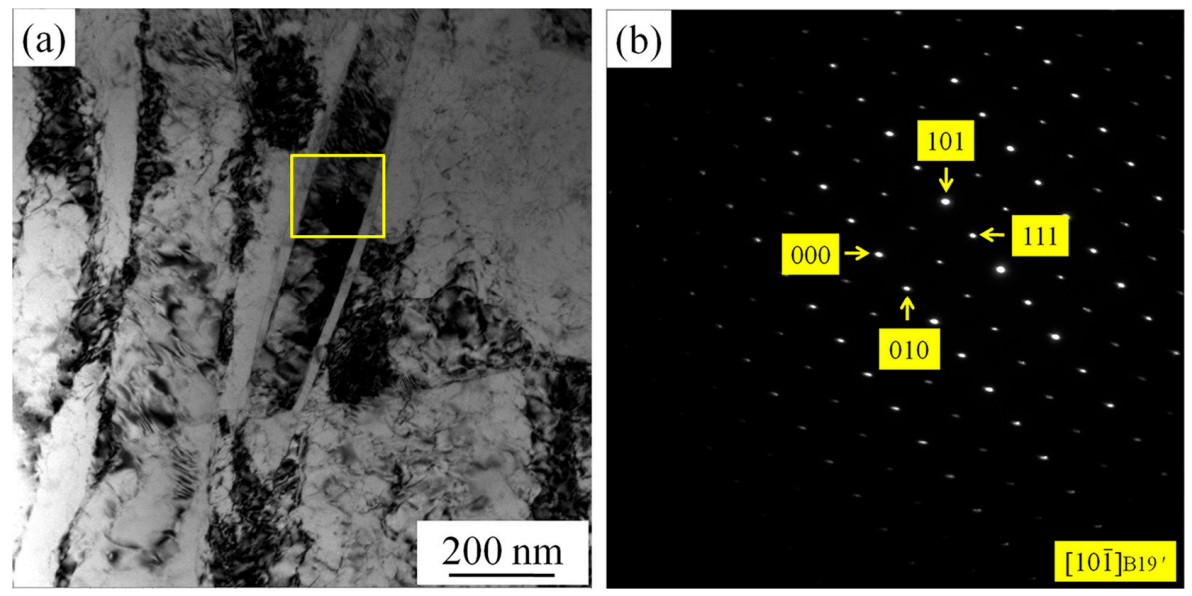

Figure 5. TEM micrographs of NiTiCu SMA subjected to compression deformation at $700{ }^{\circ} \mathrm{C}$ : (a) Bright field image showing the existence of dislocation substructures in martensite laths; (b) Diffraction pattern of (a).
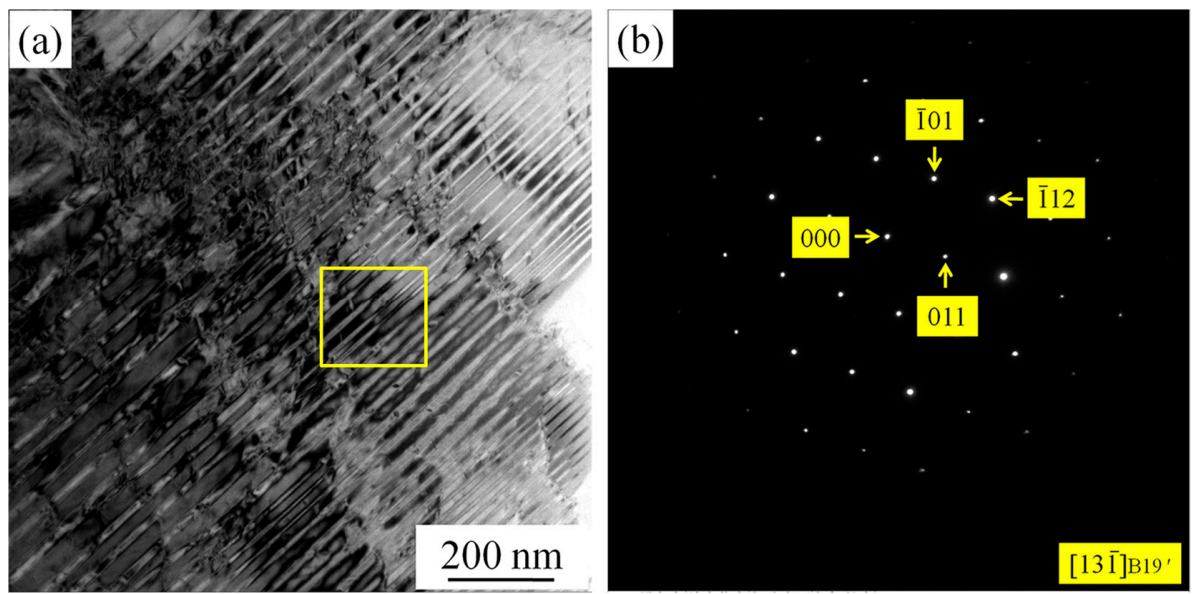

Figure 6. TEM micrographs of NiTiCu SMA subjected to compression deformation at $800^{\circ} \mathrm{C}$ : (a) Bright field image showing the existence of martensite twins; (b) Diffraction pattern of (a).
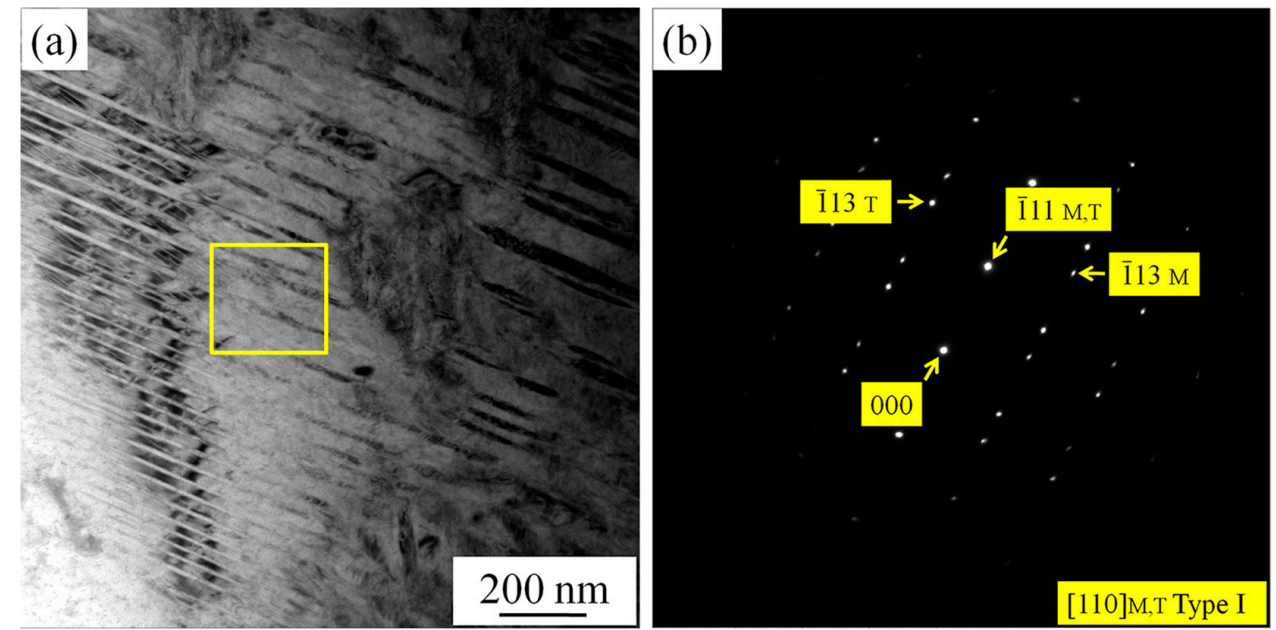

Figure 7. TEM micrographs of NiTiCu SMA subjected to compression deformation at $900{ }^{\circ} \mathrm{C}$ : (a) Bright field image showing the existence of martensite twins; (b) Diffraction pattern of (a). 

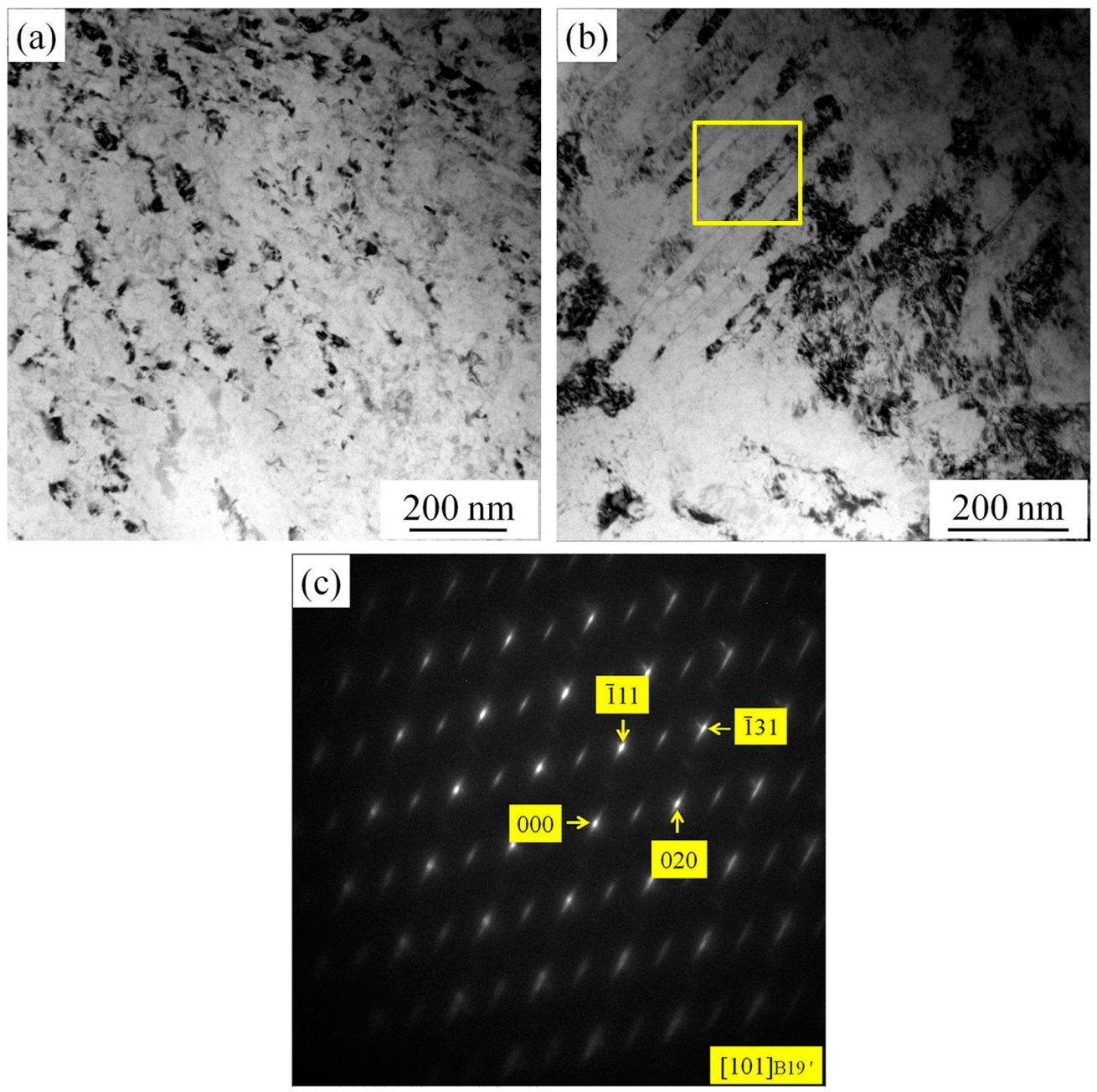

Figure 8. TEM micrographs of NiTiCu SMA subjected to compression deformation at $1000^{\circ} \mathrm{C}$ : (a) Bright field image showing no martensite laths; (b) Bright field image showing the existence of martensite laths; (c) Diffraction pattern of (b).

\section{Conclusions}

The deformation behavior and microstructure evolution of NiTiCu SMA, which possesses martensite phase at room temperature, were investigated based on a uniaxial compression test at the temperatures of $700 \sim 1000{ }^{\circ} \mathrm{C}$ and at the strain rates of $0.0005 \sim 0.5 \mathrm{~s}^{-1}$. The following conclusions can be drawn:

(1) The constitutive equation of NiTiCu SMA based on the Zener-Hollomon parameter was established in order to describe the flow characteristic of NiTiCu SMA. The results show that the flow stress of NiTiCu SMA depends on the strain rates. Depending on temperatures, DRV or DRX are the main mechanisms for the plastic deformation of NiTiCu SMA at elevated temperatures.

(2) The microstructures resulting from DRV or DRX have a significant influence on the substructures in the martensite phase of the NiTiCu SMA sample at room temperature. Dislocations become the dominant substructures of martensite in the NiTiCu SMA specimen undergoing compression at $700{ }^{\circ} \mathrm{C}$. Martensite twins are dominant in the NiTiCu SMA specimen undergoing compression at 800 and $900^{\circ} \mathrm{C}$. Martensite twins are not observed in the NiTiCu SMA specimen undergoing compression at $1000{ }^{\circ} \mathrm{C}$.

(3) Dislocation substructures resulting from DRV, such as dislocation cells and subgrain boundaries, are able to suppress the formation of martensite twins in the martensite laths of NiTiCu SMA. 
The size of dynamic recrystallized grains has an effect on the formation of martensite twins. Martensite twins are not easily formed in larger dynamic recrystallized grain, since the constraint of the grain boundaries plays a weak role. However, in smaller dynamic recrystallized grain, martensite twins are induced in order to accommodate the occurrence of the transformation from austenite phase to martensite phase.

Acknowledgments: The work was financially supported by National Natural Science Foundation of China (Nos. 51475101, 51305091 and 51305092).

Author Contributions: Shuyong Jiang wrote the manuscript; Dong Sun performed TEM analysis; Yanqiu Zhang established constitutive equation; Li Hu processed experimental data.

Conflicts of Interest: The authors declare no conflict of interest.

\section{References}

1. Jani, J.M.; Leary, M.; Subic, A.; Gibson, M.A. A review of shape memory alloy research, applications and opportunities. Mater. Des. 2014, 56, 1078-1113. [CrossRef]

2. Basu, R.; Eskandari, M.; Upadhayay, L.; Mohtadi-Bonab, M.A.; Szpunar, J.A. A systematic investigation on the role of microstructure on phase transformation behavior in Ni-Ti-Fe shape memory alloys. J. Alloys Compd. 2015, 645, 213-222. [CrossRef]

3. Choi, E.; Hong, H.K.; Kim, H.S.; Chung, Y.S. Hysteretic behavior of NiTi and NiTiNb SMA wires under recovery or pre-stressing stress. J. Alloys Compd. 2013, 577S, S444-S447. [CrossRef]

4. Wang, M.J.; Jiang, M.Y.; Liao, G.Y.; Guo, S.; Zhao, X.Q. Martensitic transformation involved mechanical behaviors and wide hysteresis of NiTiNb shape memory alloys. Prog. Natl. Sci. Mater. Int. 2012, 22, 130-138. [CrossRef]

5. Nespoli, A.; Passaretti, F.; Villa, E. Phase transition and mechanical damping properties: A DMTA study of NiTiCu shape memory alloys. Intermetallics 2013, 32, 394-400. [CrossRef]

6. Basu, R.; Mohtadi-Bonab, M.A.; Wang, X.; Eskandari, M.; Szpunar, J.A. Role of microstructure on phase transformation behavior in Ni-Ti-Fe shape memory alloys during thermal cycling. J. Alloys Compd. 2015, 652, 459-469. [CrossRef]

7. Choudhary, N.; Kaur, D. Shape memory alloy thin films and heterostructures for MEMS applications: A review. Sens. Actuators A 2016, 242, 162-181. [CrossRef]

8. Kaur, N.; Kaur, D. NiTiCu/AlN/NiTiCu shape memory thin film heterostructures for vibration damping in MEMS. J. Alloys Compd. 2014, 590, 116-124. [CrossRef]

9. Kotil, T.; Sehitoglu, H.; Maier, H.J.; Chumlyakov, Y.I. Transformation and detwinning induced electrical resistance variations in NiTiCu. Mater. Sci. Eng. A 2003, 359, 280-289. [CrossRef]

10. Saikrishna, C.N.; Ramaiah, K.V.; Bhaumik, S.K. Effects of thermo-mechanical cycling on the strain response of Ni-Ti-Cu shape memory alloy wire actuator. Mater. Sci. Eng. A 2006, 428, 217-224. [CrossRef]

11. Nespoli, A.; Villa, E.; Besseghini, S. Characterization of the martensitic transformation in Ni50-xTi50Cux alloys through pure thermal measurements. J. Alloys Compd. 2011, 509, 644-647. [CrossRef]

12. Colombo, S.; Cannizzo, C.; Gariboldi, F.; Airoldi, G. Electrical resistance and deformation during the stress-assisted two-way memory effect in Ni45Ti50Cu5 alloy. J. Alloys Compd. 2006, 422, 313-320. [CrossRef]

13. Sharifi, E.M.; Karimzadeh, F.; Kermanpur, A. The effect of cold rolling and annealing on microstructure and tensile properties of the nanostructured Ni50Ti50 shape memory alloy. Mater. Sci. Eng. A 2014, 607, 33-37. [CrossRef]

14. Tadayyon, G.; Guo, Y.; Mazinani, M.; Zebarjad, S.M.; Tiernan, P.; Tofail, S.A.M.; Biggs, M.J.P. Effect of different stages of deformation on the microstructure evolution of Ti-rich NiTi shape memory alloy. Mater. Charact. 2017, 125, 51-66. [CrossRef]

15. Yeom, J.T.; Kim, J.H.; Hong, J.K.; Kim, S.W.; Park, C.H.; Nam, T.H.; Lee, K.Y. Hot forging design of as-cast NiTi shape memory alloy. Mater. Res. Bull. 2014, 58, 234-238. [CrossRef]

16. Sehitoglu, H.; Karaman, I.; Zhang, X.; Hong, K.; Chumlyakov, Y.; Kireeva, I. Deformation of NiTiCu shape memory single crystals in compression. Metall. Mater. Trans. A 2001, 32A, 477-489. [CrossRef]

17. Morakabati, M.; Kheirandish, S.; Aboutalebi, M.; Taheri, A.K.; Abbasi, S.M. The effect of Cu addition on the hot deformation behavior of NiTi shape memory alloys. J. Alloys Compd. 2010, 499, 57-62. [CrossRef] 
18. Morakabati, M.; Aboutalebi, M.; Kheirandish, S.; Taheri, A.K.; Abbasi, S.M. Hot tensile properties and microstructural evolution of as cast NiTi and NiTiCu shape memory alloys. Mater. Des. 2011, 32, 406-413. [CrossRef]

19. Mirzadeh, H.; Parsa, M.H. Hot deformation and dynamic recrystallization of NiTi intermetallic compound. J. Alloys Compd. 2014, 614, 56-59. [CrossRef]

20. Yin, X.Q.; Park, C.H.; Li, Y.F.; Ye, W.J.; Zuo, Y.T.; Lee, S.W.; Yeom, J.T.; Mi, X.J. Mechanism of continuous dynamic recrystallization in a $50 \mathrm{Ti}-47 \mathrm{Ni}-3 \mathrm{Fe}$ shape memory alloy during hot compressive deformation. J. Alloys Compd. 2017, 693, 426-431. [CrossRef]

21. Jiang, S.Y.; Zhang, Y.Q.; Zhao, Y.N. Dynamic recovery and dynamic recrystallization of NiTi shape memory alloy under hot compression deformation. Trans. Nonferrous Met. Soc. China 2013, 23, 140-147. [CrossRef]

22. Etaati, A.; Dehghani, K. A study on hot deformation behavior of Ni-42.5Ti-7.5Cu alloy. Mater. Chem. Phys. 2013, 140, 208-215. [CrossRef]

23. Shamsolhodaei, A.; Zarei-hanzaki, A.; Ghambari, M.; Moemeni, S. The high temperature flow behavior modeling of NiTi shape memory alloy employing phenomenological and physical based constitutive models: A comparative study. Intermetallics 2014, 53, 140-149. [CrossRef]

24. Jiang, S.Y.; Zhang, Y.Q.; Zhao, Y.N.; Tang, M.; Yi, W.L. Constitutive behavior of Ni-Ti shape memory alloy under hot compression. J. Cent. South Univ. 2013, 20, 24-29. [CrossRef]

25. Zhang, Y.Q.; Jiang, S.Y.; Zhao, Y.N.; Liu, S.W. Constitutive equation and processing map of equiatomic NiTi shape memory alloy under hot plastic deformation. Trans. Nonferrous Met. Soc. China 2016, 26, 2152-2161. [CrossRef]

26. Zhang, Y.; Jiang, S.; Chen, C.; Hu, L.; Zhu, X. Hot workability of a NiTiCu shape memory alloy with acicular martensite phase based on processing maps. Intermetallics 2017, 86, 94-103. [CrossRef]

(C) 2017 by the authors. Licensee MDPI, Basel, Switzerland. This article is an open access article distributed under the terms and conditions of the Creative Commons Attribution (CC BY) license (http:/ / creativecommons.org/licenses/by/4.0/). 